\title{
Reabilitação pós-infecção por Covid-19
}

O Covid -19 deixa sintomas de longo prazo pós-infecção pelo vírus, são grandes os desafios a serem enfrentados por pesquisadores, médicos, vem buscando com o objetivo de preservar a capacidade funcional, melhorar a qualidade de vida, possibilitar o retorno do individuo as atividades sociais oferecendo cuidado seguro e efetivo. Porém é necessário acompanhar o que ocorre após a fase aguda da infecção. As consequências em longo prazo dessa infecção ainda estão sendo observadas e as doenças pré-existentes ou adquiridas podem agravar a saúde da população. Entretanto, foi realizada uma pesquisa, revisão qualitativa exploratória da literatura, tendo em vista analisar e investigar os impactos da COVID-19 pós - infecção. Como critérios de inclusão para seleção dos artigos foram utilizados: os disponíveis gratuitamente na íntegra, publicados no ano de 2020. Para realizar a busca dos artigos, foi realizado um levantamento eletrônico, onde as principais fontes utilizadas. Diante ao que foi exposto, evidenciou-se a necessidade de ampliar a discussão sobre a COVID-19, na perspectiva de reduzir cada vez mais o número de infectados pelo vírus, assim como, é fundamental traçar um plano de cuidados, a fim de melhorar as funções psicológicas e fisiológicas desses pacientes, buscando medidas que reduzam os efeitos do vírus, diminuindo ou impedindo o surgimento de desconforto físico, social e emocional nesses indivíduos pós- infecção.

Palavras-chave: Covid-19; Cuidados pós-infecção; Assistência ao Paciente.

\section{Rehabilitation after Covid-19 infection}

Covid 19 leaves long-term symptoms after infection by the virus, there are great challenges to be faced by researchers, doctors, it has been seeking to preserve functional capacity, improve quality of life, enable the individual to return to social activities offering safe and effective care. However, it is necessary to monitor what happens after the acute phase of the infection. The long-term consequences of this infection are still being observed and pre-existing or acquired diseases can worsen the health of the population. However, a research was carried out, an exploratory qualitative review of the literature, with a view to analyzing and investigating the impacts of COVID-19 after infection. As inclusion criteria for the selection of articles were used: those freely available in full, published in the year 2020. In order to search for the articles, an electronic survey was carried out, where the main sources used. In view of the above, the need to broaden the discussion on COVID-19 was evidenced, with the perspective of reducing more and more the number of people infected by the virus, as well as, it is essential to draw up a care plan in order to improve the psychological and physiological functions of these patients, seeking measures to reduce the effects of the virus, reducing or preventing the appearance of physical, social and emotional discomfort in these individuals after- infection.

Keywords: Covid-19; Care after infection; Patient assistance.

Topic: Infectologia

Reviewed anonymously in the process of blind peer.
Received: 29/03/2021

Approved: 09/04/2021

Franderta Corado Lopes (iD)

Faculdade Presidente Antônio Carlos, Brasil

http://lattes.cnpq.br/6355210330921183

http://orcid.org/0000-0002-4482-1797

franderta flower@hotmail.com 


\section{INTRODUÇÃO}

A pandemia do COVID-19 trouxe diversos impactos ao mundo, ocasionando altas taxas de internação hospitalar e de mortalidade. Devido ao aumento do número de casos em todo o mundo, foi decretado pela Organização Mundial da Saúde, um estado de pandemia. O Covid-19 também trouxe grande impacto funcional aos que se recuperaram da doença, especialmente àqueles que necessitaram de internação em Unidade de Terapia Intensiva.

Conforme afirma Zhang et.al. (2020) as sequelas mais graves após o tratamento da Síndrome Respiratória Aguda Grave (SARS) são a fibrose pulmonar e a necrose da cabeça do fêmur, induzida por grandes doses de pulsoterapia com esteróides.

Huang (2020) afirma que o Covid-19 é uma doença que pode causar uma importante lesão pulmonar, exigindo hospitalização para uso de oxigênio e, no último caso, internação em unidade de terapia intensiva com uso de ventilação mecânica invasiva. Diante disso, é um vírus que deixa várias sequelas no paciente pós-tratamento surgindo complicações pós-internação hospitalar, a longo período, principalmente nos pacientes mais graves que necessitam de tratamento em unidade de terapia intensiva, o que cria a necessidade de reabilitação pós-internação. Conforme OPAS (2020) A principal sequela nos pacientes que tiveram quadro clínico grave de Covid-19 é a fibrose pulmonar.

Assim como assevera Queiros (2020), que cerca de 17\% dos pacientes que são hospitalizados com a forma severa do Covid-19, necessitam de ventilação mecânica e cuidados intensivos. Sabe-se também que a infecção por Covid-19 não é somente uma infecção de acometimento respiratório, mas também de outros órgãos e sistemas.

Após a alta hospitalar de pacientes lesionados pelo Covid- 19 existem uma grande necessidade de assistência e orientação profissional para reabilitação. O tratamento adequado da síndrome de dor crônica que vem acometendo grande parte dessa população torna-se imprescindível para um retorno mais rápido e adequado as atividades laborais e sociais. Apesar dos tratamentos clínicos atuais serem bastante significativo na boa evolução da doença aguda, um novo desafio emerge em relação a cuidados das sequelas promovidas pelo vírus.

Nunes (2020) discorre que os pacientes da Covid-19 quando recebem alta hospitalar podem começar uma nova batalha, isso porque estudos feitos com pessoas que contraíram a doença observaram sequelas, mesmo após a cura, e até mesmo nos casos menos graves. Os sintomas mais comuns após a doença são tosse por esforço, fadiga muscular, dispnéia, cansaço aos mínimos esforços, fraqueza generalizada, tolerância diminuída ao exercício, dores, ansiedade, depressão, falta de atenção. Isso tudo leva a uma perda da capacidade funcional e da qualidade de vida.

A justificativa para este artigo sobre a Covid 19 está no desconhecimento acerca de suas consequências. Centenas de pesquisas estão sendo realizados no mundo para encontrar um tratamento comprovadamente eficaz contra a Covid 19, os cientistas vêm estudando e desenvolvendo drogas para um tratamento eficaz. Porém de acordo com os dados apresentados pela OMS, Junto com o aparecimento da mais nova doença que domina o mundo atual, o Covid-19, surgiu complicações pós-internação hospitalar, 
assim se faz necessário uma equipe multidisciplinar de profissionais da saúde com experiência no manejo clínico de pacientes com COVID-19 pós- infecções virais, bem como estudos clínicos pós- infectado.

Nesse contexto, este estudo tem como objetivo analisar e investigar as sequelas do novo Coronavírus pós- infecção por Covid-19.

\section{METODOLOGIA}

De acordo com Migueles (2004) metodologia de pesquisa é "um conjunto de métodos e de procedimentos de pesquisa que tem por objetivo coletar, sistematizar e organizar dados de forma válida e consistente, de modo a servir de base para a interpretação científica destes". Diante disso, o presente estudo possui abordagem uma revisão qualitativa exploratória da literatura, tendo em vista analisar e investigar os impactos da COVID-19 pós-infecção. Como critérios de inclusão para seleção dos artigos foram utilizados: os disponíveis gratuitamente na íntegra, publicados no ano de 2020, foram excluídos aqueles que não responderiam a questão norteadora com base na sua leitura prévia, como também aqueles incompletos, para a busca.

Para realizar a busca dos artigos, foi realizado um levantamento eletrônico, onde as principais fontes utilizadas foram o National Center for Biotechnology Information (NCBI), Biblioteca Virtual em Saúde (BVS), Plataforma Science Direct e a Scientific Eletronic Library Online (SciELO), no segundo semestre de 2020 por meio de descritores, Reabilitação de pacientes pós Covid-19, Sequelas de recuperados da Covid19, dentre outros descritores.

\section{RESULTADOS}

Os resultados obtidos através da pesquisa, com o propósito de alcançar o objetivo geral deste trabalho, que foi analisar e investigar as sequelas do novo Coronavírus pós- infecção por Covid-19. Observamos no decorrer dos conceitos bibliográficos, onde nos mostra a importância de pesquisadores, médico vem buscando para entender e atenuar as consequências de médio e longo prazo que o vírus pode trazer para aqueles que já entraram em contato com ele.

\section{Sequelas que pacientes recuperados da Covid-19 podem ter}

Um artigo publicado em abril na revista Science destacava que um possível sinalizador das regiões mais vulneráveis do corpo seria aquelas ricas em receptores chamados ECA2 (enzima conversora da angiotensina 2).

Autópsias de pessoas mortas pela Covid-19 comprovam que o vírus é encontrado no cérebro. A principal hipótese dos especialistas é que o invasor entra nas células do sistema nervoso usando o receptor ECA2, ao qual se liga com a proteína em forma de espinho que possui; o receptor é abundante no sistema nervoso. Como as vias respiratórias são a principal entrada do patógeno no corpo, a proximidade do cérebro facilita a invasão do vírus (YASUDA, 2020).

Conforme afirma Lacerda (2020), há especialistas de diferentes áreas da medicina para saber como 
a doença, em seus estágios graves de evolução, vem agindo em diferentes sistemas e o que se pode esperar de sequelas definitivas para pacientes recuperados da doença. Todos afirmam: a Covid-19 ainda está sendo estudada, e a cada dia é uma descoberta. A Covid-19 é uma doença sistêmica. fundamentalmente respiratória, ligada a uma pneumonia viral, mas logo em seguida se viu o quanto à doença comprometia outros sistemas do corpo.

Assim como enfatiza Jaffri (2020), muitos estudos documentaram danos persistentes em muitos órgãos ou sistemas, incluindo pulmões, coração, cérebro, rins e sistema vascular, em pacientes infectados com Covid-19. O dano parece ser causado por respostas inflamatórias intensas, microangiopatia trombótica, tromboembolismo venoso e privação de oxigênio. Foi encontrada baixa saturação de oxigênio no sangue mesmo em pacientes assintomáticos e pré - sintomáticos com pneumonia por COVID-19, que foi chamada de "hipóxia silenciosa". Foi documentado que a lesão nos órgãos persiste nos pulmões, coração, cérebro e rins, mesmo em algumas pessoas que apresentavam apenas sintomas leves. 0 ritmo lento da recuperação explica prontamente a duração do que passou a ser chamado de "síndrome pós - Covid" (JAFFRI, 2020).

"A síndrome pós-Covid é um nome que foi dado para compreender o conjunto de sinais e sintomas que observamos de forma persistente nos pacientes depois da apresentação aguda da doença", explica Gustavo Prado, pneumologista do Hospital Oswaldo Cruz. O médico ressalta que o termo "síndrome pósCovid" é uma descrição muito recente na literatura médica e ainda não há dados consolidados e volumosos sobre as sequelas em longo prazo (MORALES, 2020).

Corroborando Ferraz (2020), assevera que complicações provocadas pela Covid-19 ainda são investigadas por pesquisadores e pelos médicos na linha de frente. Até agora, sabe-se que a doença é capaz de provocar inflamações no corpo todo, que comprometem o funcionamento dos pulmões, reduzem a oxigenação do sangue e causam microtrombos no sistema cardiovascular. Esse processo aumenta o risco de uma isquemia que pode levar a uma parada cardíaca, além de deixar sequelas que devem ser tratadas depois da cura. Outras consequências, identificadas em estudos mais preliminares, envolvem possíveis alterações em neurônios (FERRAZ, 2020).

Orsini et. al. (2020) ressaltam que, em relação à reabilitação de pacientes sobreviventes do Covid19, as informações começam a ser organizadas para facilitar o desempenho dos profissionais de saúde. Com base nessa premissa, o de Stanford Hall para a reabilitação pós-Covid-19 realizado por pesquisadores do Reino Unido reúne até agora as melhores evidências para a condução da reabilitação nesse novo cenário que se apresenta a todo o mundo. O documento abrange recomendações para: reabilitação pulmonar, cardiovascular, neuromusculoesquelética e neurológica, sem deixar de lado as recomendações médicas e psicológicas, diretamente relacionadas à reabilitação.

Conforme redação O Sul (2020) no cérebro a ocorrência de uma série de sintomas neurológicos que vão de confusão mental e dificuldade cognitiva a delírio também tem sido documentada entre pacientes com Covid-19. Assim como, têm sido observadas convulsões, casos de síndrome de Guillain-Barré 
(que ataca o sistema nervoso e causa fraqueza muscular) e de encefalite, a inflamação do parênquima do encéfalo. Conforme nos mostra a figura 1, os vários órgãos que o vírus pode vir a afetar, além do pulmão.

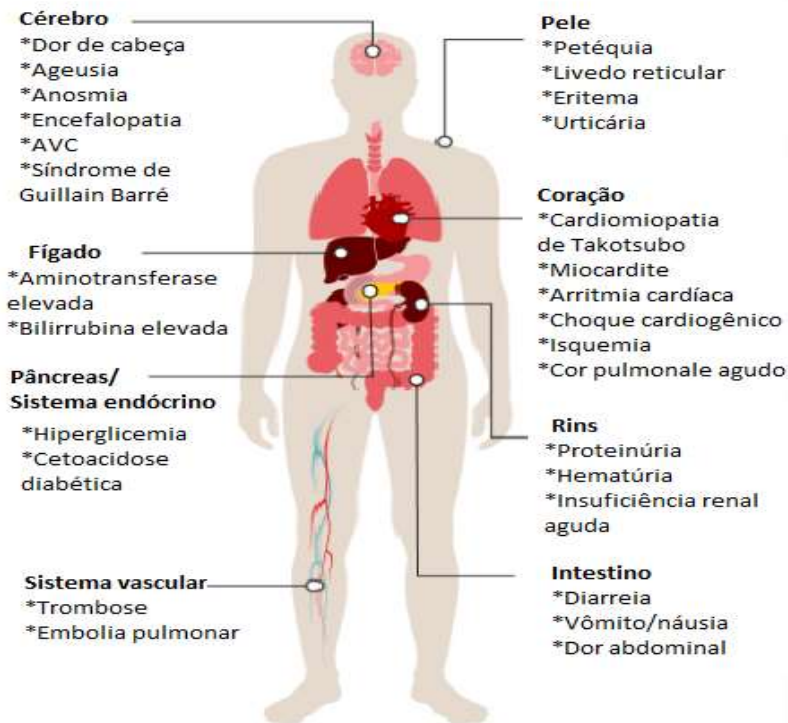

Figura 1: Manifestação da Covid 19 em outros órgãos. Fonte: BBC (2020).

Um grande esforço de pesquisa está em andamento para desenvolver uma vacina contra a Covid19, há uma variedade de abordagens investigacionais estão sendo exploradas, Entre eles estão os medicamentos antivirais (OMS, 2020). Porém a solução imediata conforme Organização Mundial da Saúde (OMS) são a prevenção através do distanciamento social, (evitando contato físico) higienização das mãos e o uso de máscara, para minimizar a propagação do vírus.

Até o momento não há medicamento específico para o tratamento da infecção humana pelo novo Coronavírus (2019-nCoV). No entanto, medidas de suporte devem ser implementadas (MINISTÉRIO DA SAÚDE, 2020). A única opção disponível é o uso de drogas antivirais de amplo espectro, como análogos de nucleosídeo e também inibidores da protease do HIV que podem atenuar a infecção por vírus até que o antiviral específico fique disponível (ROTHAN et. al., 2020).

Os médicos tentam entender quais consequências de médio e longo prazo o vírus pode trazer para aqueles que já entraram em contato com ele. Uma série de estudos divulgados nos últimos meses e a observação clínica dos profissionais que estão na linha de frente indica as possíveis sequelas que a doença pode deixar-ainda que não seja possível dizer se elas são temporárias ou perenes. (MOTA, 2020)

Segundo afirma Perrin et. al. (2020) a investigação dos sintomas manifestados após a COVID-19, uma vez que o desenvolvimento de técnicas eficientes e de baixo custo para tratar e melhorar a qualidade de vida dos pacientes acometidos pelas sequelas de longa duração da Covid-19 será fundamental para ajudar a reduzir a pressão sobre os serviços de saúde.

O documento Rehabilitation considerations during the COVID-19 outbreak é enfático ao afirmar que os esforços do governo para oferecer reabilitação aos pacientes que sobrevivem ao COVID-19 devem ser os mesmos realizados quanto à oferta de leitos hospitalares. Além dos centros de reabilitação, dos programas ambulatoriais, dos atendimentos 
domiciliares, a pandemia nos mostrou uma potencialidade pertinente ao momento atual, a telessaúde, incluindo telemedicina e tele-reabilitação (ORSINI, 2020).

Troncoso (2020) assevera que em síntese, é muito provável que os que sobrevivem à hospitalização, e principalmente aos cuidados intensivos, estejam em risco particular de futuramente vir a sofrer com dores crônicas de diversos tipos. As sequelas que poderiam provocar isso emanam de seis fatores, segundo três pesquisadores britânicos num artigo publicado British Journal of Anesthesia. Eles são resumidos na figura 2 .

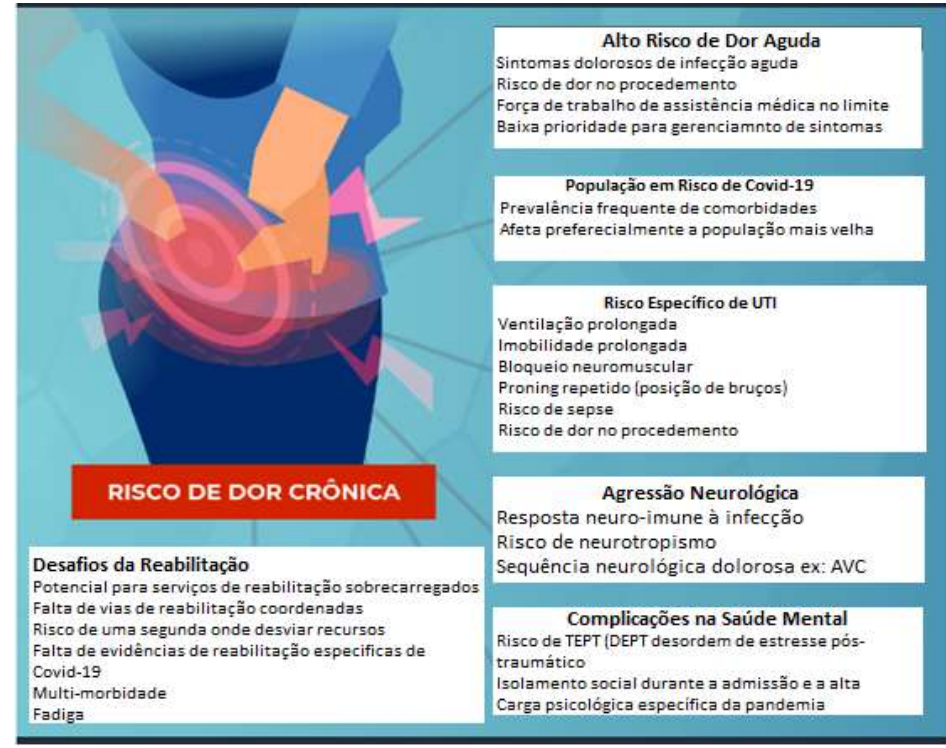

Figura 2: Fatores de risco potenciais para o desenvolvimento de dor crônica após COVID-19. Fonte: British Jornal of Anesthesia (2020).

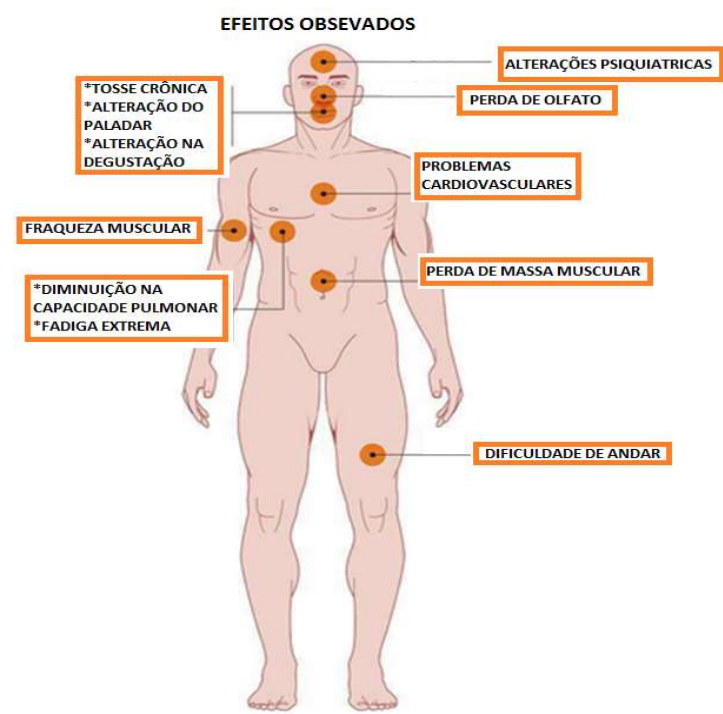

Figura 3: Áreas e Órgãos Que Podem Ser Afetados Após a Infecção Pela Covid-19. Fonte: Eufrásio (2020).

Orsini et. al. (2020) discorre que a reabilitação sempre foi descrita como um processo multidisciplinar e, em pacientes sobreviventes ao Covid-19, devido ao fato de ser uma condição clínica e funcional de recente descoberta, será extremamente importante para os profissionais trocarem o máximo de informações possíveis, para que os indivíduos retomem as suas atividades diárias, o mais próximo possível do que eram anteriormente.

São muitos os sintomas apresentado pelos pacientes que se recuperaram da Covid-19. Após 
enfrentarem um quadro mais grave, sobreviventes podem depender de equipe multiprofissional para lidar com as sequelas da doença. Conforme nos mostra a figura 3 às possíveis consequência pós- infecção.

Eufrásio (2020), ainda afirma que o fato de a doença ser nova mantém alguns aspectos como incógnita. Um deles é o impacto sofrido pelo organismo durante a recuperação. Muitos pacientes têm apresentado características persistentes ou sequelas em diferentes partes do corpo, e o tempo necessário até a reabilitação completa, ainda se encontra em estudo em todo o mundo.

\section{DISCUSSÕES}

Os resultados apresentados nesse estudo apontaram para uma necessidade de cuidados, pós- alta hospitalar, conforme postula o Sistema Nacional de Saúde Inglês (2020) aponta que os pacientes que sobreviveram à COVID-19 podem precisar de cuidados imediatos e de longo prazo, após a alta hospitalar, envolvendo cuidados físicos, neuropsicológicos e sociais: respiratórios (pacientes que necessitam de oxigênio, reabilitação pulmonar, doença vascular pulmonar, traqueostomia e suas feridas, disfagia, tosse crônica, fibrose pulmonar, bronquiectasia, investigação da função pulmonar e acompanhamento das anormalidades presentes nos exames de imagem); cardiologia (reabilitação cardíaca e acompanhamento imediato para complicações cardíacas relacionadas à COVID-19); urologia (cateteres urinários); neuromusculares (fraqueza muscular e neuropatia); endocrinologia (diabetes); função Geral e Bem-Estar (dieta/nutrição, úlceras de pressão, fadiga, CFS/ME, cuidados odontológicos, problemas de fala e linguagem); psicológicos e Neuropsicológicos (delírio, dificuldades cognitivas, demência); saúde Mental (transtorno de estresse pós-traumático (PTSD), depressão, transtornos de ansiedade, recorrência de problemas de saúde mental prévios, insônia); sociais (prejuízo nas atividades de vida diária) (SES 2020).

Conforme salienta Presto (2020), para tentar ajudar no manejo da reabilitação destes pacientes, um estudo em que apresentou as experiências de centros de reabilitação de 11 países da Europa e América do Norte. Este trabalho observou que as principais sequelas decorrentes da Covid-19 são em ordem de prevalência.

Diante disso, é necessário estabelecer um comitê de ética, a fim de antecipar e enfrentar os desafios futuros relacionados à infecção pós Covid em nível nacional, para atendimento às necessidades de tratamento tanto físico mental e social dos pacientes em relação a cuidados das sequelas promovidas pelo vírus.

\section{CONCLUSÕES}

Por se tratar de um vírus ainda novo, muitos esforços estão sendo despendidos em todo o mundo, comprovações científicas estão em andamento através de uma vacina que tenha eficácia de $100 \%$, estamos na expectativa com a vacina produzida com 95\% de eficácia, esperamos que a erradicação do vírus esteja próximo. Porém só a cura do vírus não resolve o problema dos pacientes que foram infectados pelo vírus. O terreno da prática da assistência aos pacientes pós-infecção ainda é incerto, contudo, toda 
integração possível trará a esse cenário de decisões mais assertivas e informações compartilhadas entre profissionais.

Após a alta hospitalar, a intervenção em domicílio e na comunidade, no contexto da reabilitação, têm se apresentado como uma necessidade importante dos usuários. No futuro, a disponibilidade de novos conhecimentos sobre o impacto da doença e suas repercussões respiratórias, cardiovasculares, metabólicas e sistêmicas irá nortear com maior precisão a tomada de decisões sobre as assistências pós COVID-19, no processo de reabilitação e a reintegração na sociedade.

É preciso uma equipe multiprofissional de reabilitação, pós-alta hospitalar, em especial dos pacientes graves e críticos, pois poderá ter retardo da recuperação funcional desses pacientes, assim como redução da qualidade de vida e maior necessidade de internações hospitalares e, consequentemente, haverá necessidade de maior investimento público e privado no que tange ao tratamento a longo prazo para melhoria e qualidade destes pacientes.

Diante ao que foi exposto, evidenciou-se a necessidade de ampliar a discussão sobre a COVID-19, na perspectiva de reduzir cada vez mais o número de infectados pelo vírus, assim como, é fundamental traçar um plano de cuidados, a fim de melhorar as funções psicológicas e fisiológicas desses pacientes, buscando medidas que reduzam os efeitos do vírus, diminuindo ou impedindo o surgimento de desconforto físico, social e emocional nesses indivíduos pós- infecção.

\section{REFERÊNCIAS}

CAMPOS, M. R.; SCHRAMM, J. M. A.; EMMERICK, I. C.; RODRIGUES, J. M.; AVELAR, F. G.; PIMENTEL, T. G.. Carga de doença da COVID-19 e de suas complicações agudas e crônicas: reflexões sobre a mensuração (DALY) e perspectivas no Sistema Único de Saúde. Cad. Saúde Pública, v.36, n.11, 2020. DOI:

http://doi.org/10.1590/0102311X00148920

EUFRÁSIO, J.. Sequelas em recuperados da Covid-19 são comuns; veja as mais frequentes. Correio Braziliense, 2020.

FERRAZ, A.. Complicações da Covid-19 no corpo intrigam a ciência e desafiam o sistema de saúde. Folha-PE, 2020.

HUANG, X.; WEI, F.; HU, L.; WEN, L.; CHEN, K.. Epidemiology and clinical characteristics of COVID-19. Arch Iran Med, v.23, n.4, p.268-71, 2020. DOI:

https://doi.org/10.34172/aim.2020.09

JAFFRI, A.; JAFFRI, U. A.. Post-intensive care syndrome after COVID-19: a crisis after a crisis?. NCBI, v.49, n.6, p.883-884, 2020.

LACERDA, P.. Sequelas da Covid-19: complicações em vários órgãos indicam uma doença sistêmica. O Globo, 2020.

MIGUELES, C.. Pesquisa: por que administradores precisam entender disso?. 2 ed. Rio de Janeiro: E-Papers, 2004.

MOTA, C. V.. Coronavírus: a longa lista de possíveis sequelas da Covid-19. BBC News Brasil, 2020.

MORALES, J.. Síndrome pós-Covid? Entenda as sequelas da doença. Guia do Estudante, 2020.
OPAS. Pandemia de COVID-19, doença causada pelo novo Coronavírus. OPAS, 2020.

NUNES, C.. Mesmo curados, pacientes da Covid-19 apresentam sequelas. 2020.

ORSINI, M.; NASCIMENTO, J. S. F.; NUNES, N. S. M.; NASCIMENTO, J. K. F.; CASTRO, R. R. T.; AZIZI, M. A. A.; SANT' ANNA JR, M.. Reabilitação de pacientes sobreviventes ao COVID-19: O próximo desafio. Fisioterapia, v.21,n.4, p.3345. DOI: https://doi.org/10.33233/fb.v21i4.4318

O SUL. Pulmão, coração, rins e até o cérebro: a lista de órgãos afetados pelo Coronavírus. O SUL, 2020.

OMS. Plano de P\&D da OMS: consulta informal sobre priorização de candidatos a agentes terapêuticos para uso na nova infecção por Coronavírus em 2019. Genebra: Organização Mundial da Saúde, 2020.

PERRIN, R.; RISTE, L.; WALTHER, A.; HEALD, A.; HANN, M.; MUKHERJEE, A.. Into the looking glass: post-viral syndrome post COVID-19. Med Hypotheses.

PRESTO, B.. Reabilitação pulmonar pós-alta hospitalar na Covid-19. Sobrasp, 2020.

QUEIROZ, G.. Dor crônica e reabilitação pós-infecção por Covid-19. Peb Med, 2020.

ROTHAN, H. A.; BYRAREDDY, S. N.. The epidemiology and pathogenesis of Coronavírus disease (COVID-19) outbreak. Journal of autoimmunity, v.109, p.102-433, 2020. 
DOURADO, P.; RAMOS, A.; LIMA, A.; VIEIRA, L.. Síndrome

Pós Covid-19. Secretaria do Estado da Saúde-GO, 2020.

TRONCOSO, J.. A dor crônica na recuperação da Covid-19. Dor Crônica, 2020.
ZHANG, P.; LI, J.; LIU, H.; HAN, N.; JU, J.; KOU, Y.; LEI, C.; JIANG, M.; PAN, F.; ZHENG, Y.; ZHANCHENG, G.; BAOGUO, J.. Long-term bone and lung consequences associated with hospital-acquired severe acute respiratory syndrome: a 15year follow-up from a prospective cohort study. Bone Research, v.8, n.8, 2020. DOI: https://doi.org/10.1038/s41413-020-0084-5

A CBPC - Companhia Brasileira de Produção Científica (CNPJ: 11.221.422/0001-03) detém os direitos materiais desta publicação. Os direitos referem-se à publicação do trabalho em qualquer parte do mundo, incluindo os direitos às renovações, expansões e disseminações da contribuição, bem como outros direitos subsidiários. Todos os trabalhos publicados eletronicamente poderão posteriormente ser publicados em coletâneas impressas sob coordenação da Sustenere Publishing, da Companhia Brasileira de Produção Científica e seus parceiros autorizados. Os (as) autores (as) preservam os direitos autorais, mas não têm permissão para a publicação da contribuição em outro meio, impresso ou digital, em português ou em tradução. 